Prescribing is a complex skill, requiring much more that familiarity with pill packets and knowing the difference between Femodene ${ }^{\circledR}$ and Minulet ${ }^{\circledR}$ (of course, there is none!) Until such as time as prescribing is included within the specialist nurse education programmes, to ensure that good and safe practice is in place, and also to protect nurses and their patients, we cannot assume that all nurses are equally competent and skilled. The current programme for nurse prescribing may not be perfect, but it does, along with continuing professional development, ensure that there is evidence of competence to practice. PGDs are without doubt a 'second best' to prescribing, but they can offer, when properly written, an effective guideline for nurses to issue contraception. We know, of course, that blind adherence to a policy does not 'cover' us against any eventuality. It is following best evidence-based practice that does this, and a good PGD should be doing this.

So, let's look to the future and not get stuck in the past. Nurse prescribing is here to stay, and to expand. I'm sure that eventually all nurses will be prescribers; but in the meantime, let's celebrate the achievements of those nurses who have successfully completed the programme, and support those who wish to. The future of nursing has no place for those who believe that just by doing something for a number of years qualifies them to take on extended roles without any evidence of competence.

Sally Kelsey, RGN, BSc

Lead Nurse Specialist, and Contraception and Reproductive Health, Havering PCT, 17 Norman Road, Hornchurch, Essex RM11 1LN, UK. E-mail: sally.kelsey@haveringpct.nhs.uk

Jeanie Smith, RGN

Deputy Lead Nurse, Contraception and Reproductive Health Havering PCT, UK. E-mail: jeanie.smith@haveringpct.nhs.uk

Reference

Young F. Nurse prescribing in family planning. J Fam Plann Reprod Health Care 2006: 32: 45-46.

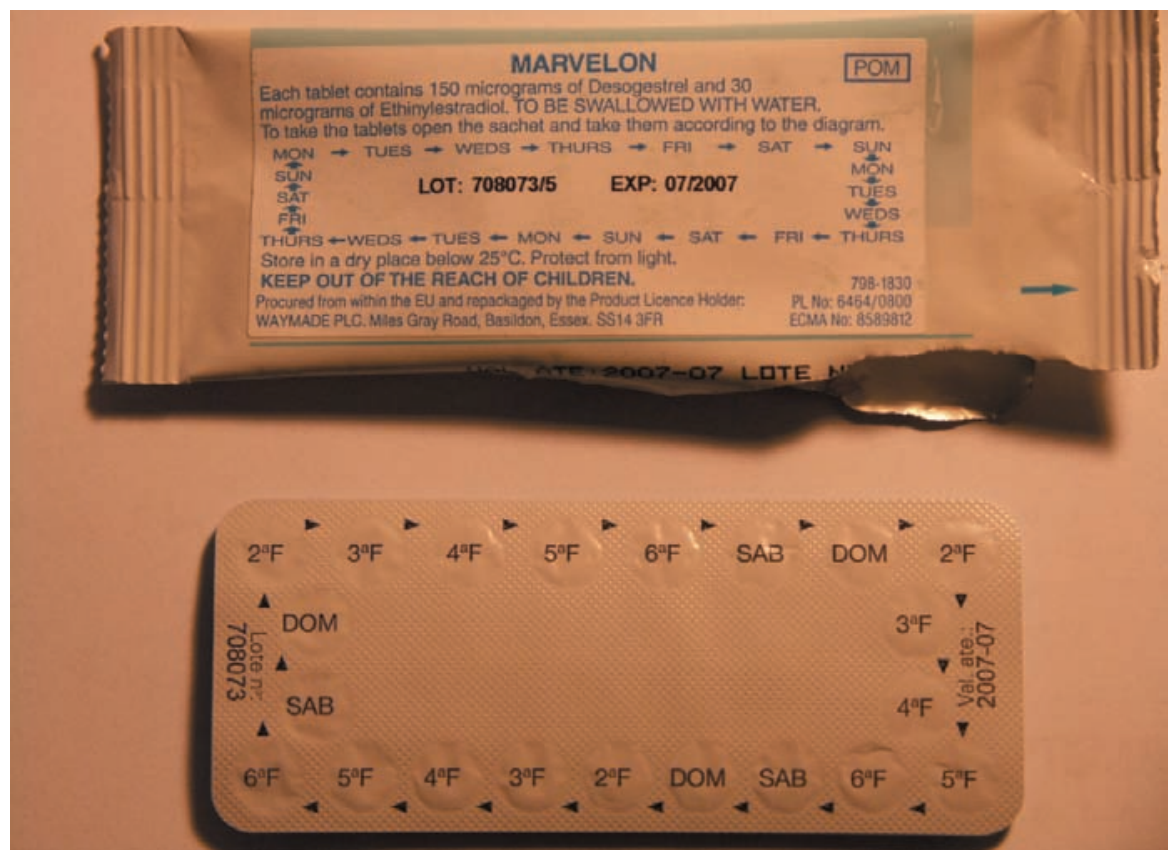

Figure 1 Example of combined oral contraceptive pill and packaging imported from Spain.

\section{Imported/foreign COCs}

Whilst I was doing a surgery in general practice a few weeks ago, a patient came in for a routine pill check. I went through all the normal questions and history, but when it came to the question "What day do you start your pill packet on?" she hesitated, and then said that she wasn't entirely sure as the pill packets were in Spanish (Figure 1)

Although I feel it is fairly east to follow a strip of pills around a packet, if you miss a pill or make a mistake then you have no idea what day you are on (unless you speak Spanish). Some women find it difficult enough to take a packet of English pills, let alone translate the packet wording as well. I think pharmacists/drug companies should not be allowed to buy cheaper foreign imports, especially with the combined pill which is dayspecific, or they should make sure that the wording on each packet is translated into English.

Ewan Bumpstead, MRCGP, DFFP

General Practitioner, Wycombe Hospital, Family Planning, Oueen Alexander Road, High Wycombe, Bucks HP11 2TT, UK. E-mail: ewanbumpstead@dsl.pipex.com

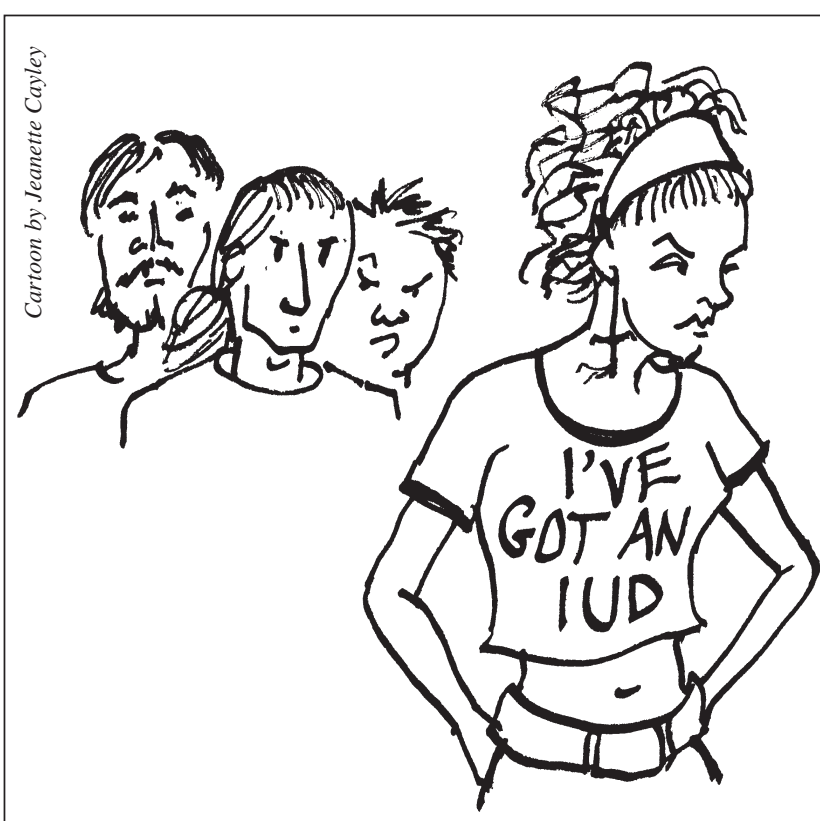

SUSPICIOUS OF ANYTHING OF A HIDDEN NATURE

\section{JOURNAL READERSHIP SURVEY}

We would like to thank the hundreds of readers who took the time to complete and return the readership survey questionnaire included with the January 2006 issue of the Journal. The detailed and wide-ranging comments will be very useful for the Editor and Editorial Team in planning the future direction and development of the Journal. The results are currently being analysed, and a full report of the survey findings will be published in the July issue.

The winner of the prize draw, and the lucky recipient of $£ 100$ of Marks and Spencer vouchers, is Dr C Sloan from Cardiff, UK. 